\title{
Epidemiology of meningococcal meningitis in Angola, 1994-2000
}

\author{
M. GASPAR ${ }^{1}$, F. LEITE ${ }^{2}$, L. BRUMANA ${ }^{3}$, B. FÉLIX ${ }^{4}$ AND A. A. STELLA ${ }^{5 *}$ \\ ${ }^{1}$ Health Directorate, National Angolan Army, Angola \\ ${ }^{2}$ National Institute of Public Health, Angola \\ ${ }^{3}$ UNICEF, Angola \\ ${ }^{4} \mathrm{WHO}$, Angola \\ ${ }^{5}$ Interuniversity Center of Research in Developing Countries (CIRPS) - Italian co-operation \\ (insp@ebonet.net)
}

(Accepted 28 July 2001)

\section{SUMMARY}

We describe six meningococcal disease outbreaks that occurred in Angola during the period 1994-2000. In total, 7140 cases were documented. The age groups most affected were 15-29 years and 5-14 years; there were no differences in incidence between the sexes. Circulation of both serogroup A and sporadic serogroup B strains was demonstrated. Mass vaccination campaigns with $\mathrm{A}+\mathrm{C}$ meningococcal polysaccharide vaccine were implemented, except in Yambala province in 1999 where insecure conditions precluded this intervention.

Outbreaks of serogroup A meningococcal disease in Angola may indicate an extension of these epidemics outside the meningitis belt. Mass vaccination campaigns stopped the Angolan epidemics within weeks. Civil conflict and displaced persons living in crowded areas created serious difficulties for surveillance and impeded timely public health responses.

\section{INTRODUCTION}

Meningococcal meningitis is the only form of bacterial meningitis that causes epidemics. Though these can occur in any part of the world, the largest outbreaks have been observed in the sub-Saharan countries of the so called 'meningitis belt' which extends from Ethiopia in the East to Senegal in the West, as described by Lapeysonnie [1]. Sporadic infections occur in seasonal annual cycles while epidemics occur at greater intervals [2]. Epidemic cycles have become shorter and more irregular since the beginning of the 1980s. During the period 1970-92, it has been estimated that there were about 800000 cases in the meningitis belt countries [3].

Since the end of the 1980s, meningococcal disease

* Author for correspondence: CIRPS (Italian Co-operation), c/o Italian Embassy, Rua dos Enganos, P.O. Box 6220, Luanda, Angola. epidemics have spread outside their traditional boundaries, reaching other African countries. This could be due to climate change with extension of dry areas, increased population mobility, or could reflect the introduction of new meningococcal strains into susceptible populations [3].

Here we describe the epidemiological features of meningococcal disease in Angola in the period 1994-2000 and comment on factors affecting surveillance and the public health response to epidemics.

Angola is a Southwest African country with a total area of $1246700 \mathrm{~km}^{2}$ and an estimated population of 13 million (Angolan National Institute of Statistics, Department of Demography, 1999). The overall population density is about 10 persons per $\mathrm{km}^{2}$ of whom some 3 million are resident in Luanda, the capital city. Internal movement from rural zones where civil conflict has severely disrupted health services to densely populated areas around the largest 
cities has been continuously observed in the last years. The epidemiological surveillance system in Angola is part of the National Direction of Public Health of the Ministry of Health and is carried out at peripheral level by provincial health authorities. Conflicts and civil unrest hinder implementation of surveillance and epidemic response capacity in areas not under control.

\section{METHODS}

The investigation of the epidemics was carried out through a systematic routine, which included case ascertainment and verification, identification of the population at risk, identification of causative agent, analysis and management. Rapid assessment field teams investigated suspected cases and evaluated the need for a public health response. Suspected cases were investigated by collection and analysis of cerebrospinal fluid (Gram stain and latex agglutination test, Pastorex Meningitis Kit ${ }^{\circledR}$, Sanofi Diagnostics Pasteur, France) to identify the causative serogroup. Cerebrospinal fluid was transported to the Laboratory of the National Institute of Public Health for confirmation of identity of bacterial isolates and to determine antibiotic resistance patterns.

Yambala, a settlement with difficult access and lack of security, was affected by an outbreak during 1999. Here, information was collected by interviewing key personnel including the Municipal Administrator, the Medical Director and health technicians of the Mission Hospital, a patient from Yambala who recovered in the hospital, together with his family, a priest from the Catholic Mission $20 \mathrm{~km}$ from Yambala, the Commandant of the Military Formation in the Municipality, traditional leaders, and the Commandant of the Police. All information was cross-checked with the various sources.

When outbreaks were recognized, emergency mass vaccination campaigns with polysaccharide $\mathrm{A}+\mathrm{C}$ meningococcal vaccine were conducted in the affected areas except in Yambala.

Epidemiological analysis was carried out with Epi Info v.6.04 and Excel 97.

\section{RESULTS}

In 1994, the Epidemiological Surveillance Unit of Angola reported 2688 cases of meningococcal meningitis with 160 deaths (Global Attack Rate, GAR $230 \times 10^{5}$ inhabitants, case fatality ratio (CFR) $4 \%$ ) from two affected provinces, Cunene 1854 cases $(69 \%)$ and Huila 834 cases $(31 \%)$. Some cases were

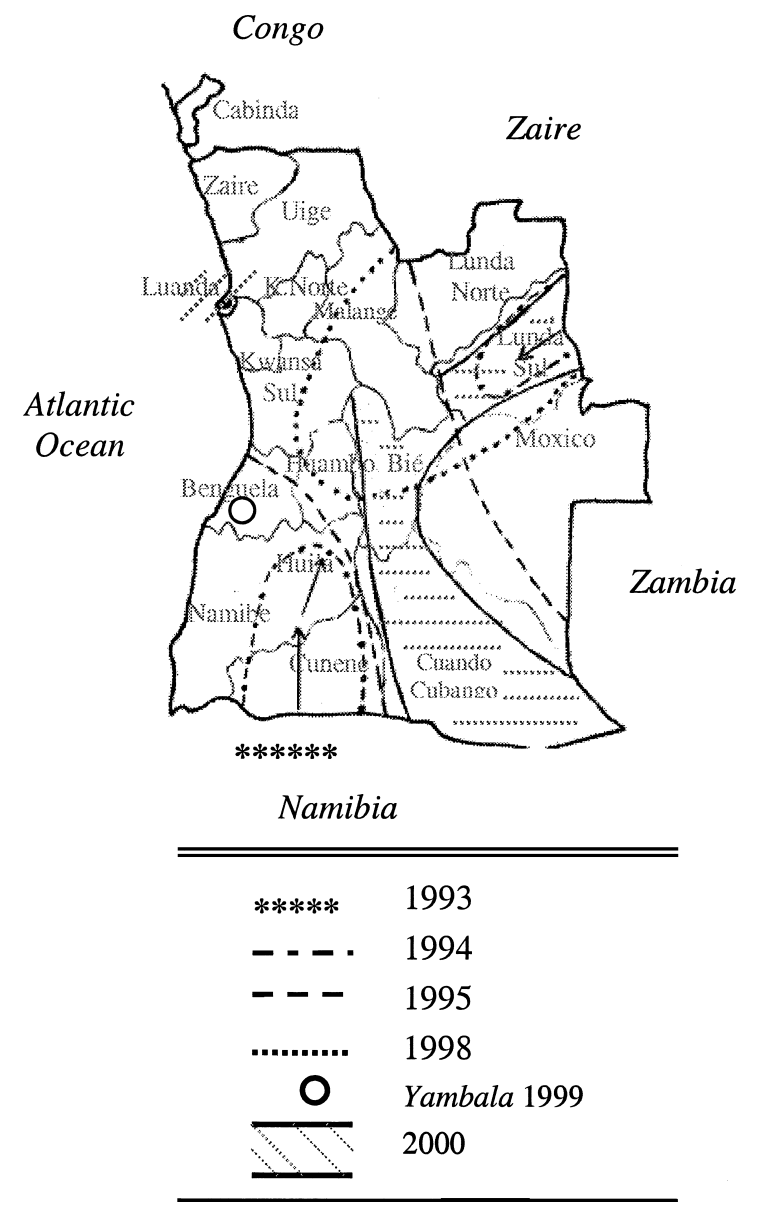

Fig. 1. Map showing the spread of meningococcal disease in Angola during the period 1993-2000.

Table 1. Incident cases of meningococcal meningitis in Angola by year, 1994-2000

\begin{tabular}{lc}
\hline \hline Year & Number of cases \\
\hline 1994 & 2688 \\
1995 & 987 \\
1996 & 467 \\
1997 & 183 \\
1998 & 2030 \\
1999 & 253 \\
2000 & 1519 \\
Total & 8127 \\
\hline \hline
\end{tabular}

found later in the same year in Lunda Sul (data not available). In 1995, Health Authorities from five provinces adjacent to the previously affected areas (Fig. 1), reported 987 cases (GAR $\left.46 \times 10^{5}\right)$. The provinces affected were Huíla (339 cases, 34\%), Namibe (372 cases, $38 \%$ ), Moxico (140 cases, $14 \%$ ) and Benguela (136 cases, 14\%). Mortality data were not available for the year 1995 .

The number of cases decreased to 467 in 1996 
$\left(\right.$ GAR $\left.12 \times 10^{5}\right)$ and to 183 in 1997 (GAR $6 \times 10^{5}$, Table 1). In this 2-year period there was a decline in the number of cases in the previously affected provinces, namely Huíla (155 in 1996 and 88 in 1999), Namibe (6 in 1996 and 0 in 1997), Moxico (26 in 1996 and 0 in 1997), Benguela (7 in 1996 and 0 in 1997) but new cases were reported in adjacent provinces (266 cases in Lunda Norte on 1996 and 7 cases in Bié in 1997). The global mortality rate (GMR) was calculated as 1.3 per $10^{5}$ inhabitants in 1996 and 0.7 per $10^{5}$ in 1997 . CFRs were $11 \%$ and $13 \%$ respectively.

Following the same geographical progression pattern, 2030 cases from nine provinces were reported in $1998\left(\right.$ GAR $\left.42 \times 10^{5}\right)$, of whom 151 died (GMR $2 \times 10^{5}$, CFR $8 \%$ ). The most severely affected provinces, located between the areas affected in previous outbreaks (Fig. 1), were Bié 881 cases (GAR $65 \times 10^{5}$, CFR $6 \%$ ), Malange 505 cases (GAR $47 \times 10^{5}$, CFR $10 \%$ ), Huambo 497 cases (GAR $27 \times$ $10^{5}$, CFR 6\%), Lunda Norte 92 cases (GAR $27 \times 10^{5}$, CFR $11 \%$ ) and Luanda 23 cases (GAR $1 \times 10^{5}$, CFR $17 \%$ ).

During the period August-September 1999, an outbreak of meningococcal disease was reported in Yambala, a settlement difficult to access in the municipality of Cubal, province of Benguela. Due to the prevailing security situation, the assessment team was not able to examine patients or collect samples for laboratory diagnosis in the field. However, according to information sources considered to be reliable, clinical features observed by witnesses were compatible with cerebrospinal meningitis. Neisseria meningitidis serogroup A was detected by latex test in six cases who were able to reach a Catholic Mission Hospital in Cubal City. Unconfirmed data suggest 253 cases with 147 deaths (GAR $361 \times 10^{5}$, CFR $58 \%$ ). The great majority ( $92 \%$ ) of the cases reported had no access to municipal health facilities.

In all of the outbreaks analysed, the age group most affected was 15-29 years followed by the age group 5-14 years, but there was no difference in attack rates between the sexes.

In the year 2000, 1519 cases with 518 deaths were reported from 6 provinces (GAR $19 \times 10^{5}$, CFR $34 \%$ ). The affected provinces were Luanda with 878 cases (GAR $38 \times 10^{5}$, CFR $50 \%$ ), Bié with 123 cases (GAR $9 \times 10^{5}$, CFR $16 \%$ ), Huambo with 349 cases (GAR $18 \times 10^{5}$, CFR $12 \%$ ), Huila with 30 cases (GAR $3 \times 10^{5}$, CFR $31 \%$ ), Kuando Kubango with 68 cases (GAR $44 \times 10^{5}$, CFR $3 \%$ ), and Lunda Sul 58 cases (GAR $31 \times 10^{5}$, CFR $16 \%$ ).
Despite the low number of laboratory examinations (14\% of total cases), circulation of Neisseria meningitidis serogroup A and sporadic cases of serogroup B were demonstrated by latex test and culture examination in the laboratory of the National Institute of Public Health from 1994.

Other than the outbreak in Yambala in 1999, all of the episodes described were managed by mass vaccination campaigns with $\mathrm{A}+\mathrm{C}$ polysacharide meningococcal vaccine. In 1997 and 1998, vaccine coverage reached $85 \%$ of the targeted population (those aged less than 30 years in the affected provinces).

\section{DISCUSSION}

The occurrence of meningococcal meningitis outbreaks in Angola may indicate the extension of epidemics outside the traditional meningitis belt. The progression of the disease in Angola suggests localized outbreaks followed by more widespread dispersal, a characteristic pattern of meningococcal disease [3, 4]. A local outbreak in a rural region can be followed by an intense and extensive epidemic during the second year of the cycle and incidence rates can remain high with successive seasonal outbreaks separated by remissions [2].

In 1993, an outbreak of meningitis was reported in Namibia. The intensive cross-border movement of people between Namibia and Cunene province could have contributed to the outbreak in Cunene province in 1994. The opening up of a new commercial airtransport route might have facilitated epidemic spread from the south to the north of the country. Local outbreaks are known to spread within countries, in particular along transport axes [5]. Extensive population movements due to civil conflict, uncontrolled urbanization and the formation of informal settlements and squatter camps, could all have played an important role in meningococcal disease transmission. Over the period studied, the epidemic cycle in Angola seemed to be characterized by shorter and more irregular intervals between outbreaks.

The age distribution of cases was consistent with that previously observed in meningococcal disease epidemics. While in endemic conditions the highest rates occur in young children, during epidemics a peak in incidence is often observed in older children, teenagers and young adults, particularly in densely populated settings such as camps for refugees and displaced populations [6]. United Nations High Commissioner for Refugees. Handbook for Emerg- 
encies. Geneva, 1982. In epidemics in Kenya, Congo, Sudan and Burkina Faso the highest attack rates occurred in those aged 20-29 years [3].

The meningitis outbreaks in Angola were attributable to $N$. meningitidis serogroup A, the main cause of meningococcal disease in Africa during both epidemic and endemic periods. However, serogroup B strains were also found, generally associated with sporadic disease. Serogroup B strains have also been identified as the cause of upsurges in Cuba, Chile, Brazil and the USA $[3,6]$.

Deficiencies in public health infrastructure due to civil war and economic decline, and the low coverage of health services, which were limited to zones under government control, represent serious impediments to surveillance and to an efficient response to epidemics. This was particularly the case in the Yambala outbreak, where mass vaccination was not possible; the outbreak there lasted for 4 months, only finishing with the onset of the rainy season. In the absence of vaccination, epidemics expand rapidly and can last for several months, usually stopping with the onset of the rains [7].

The public health consequences of mass population displacement have been extensively documented, and migrations have resulted in high rates of mortality and morbidity [8]. In such a situation the limited access to medical care is a contributing factor in outbreaks of meningococcal meningitis $[9,10]$.

In accessible areas, mass vaccination campaigns were successful in halting outbreaks within weeks. This strategy, advocated by WHO, is a cost-effective method of epidemic meningitis control exploiting the currently available polysaccharide vaccines, and assuming that campaigns can be implemented rapidly $[11,12]$. However, polysaccharide vaccines cannot be used routinely in early childhood because of the poor immunological response in infants and children aged less than 4 years $[13,14]$.

Routine surveillance remains a fundamental aspect to study trends and serogroup-specific incidence of meningococcal disease. In Angola there are formidable obstacles to efficient surveillance. Despite these difficulties, it has proved possible to detect outbreaks and to implement control measures successfully.

\section{ACKNOWLEDGEMENTS}

We wish to thank the technical staff of the National Institute of Public Health, the National Direction of
Public Health, the Health Directorate of the Angolan Army. Provincial health authorities and International Agencies took part in epidemic investigation and in training activities.

\section{REFERENCES}

1. Lapeyssonnie L. La meningite cerebrospinale en Afrique. Bull WHO 1963; 28 (suppl): 3-114.

2. Schwartz B, Moore PS, Broome CV. Global epidemiology of meningococcal disease. Clin Microbial Ver 1989; 2: S118-24.

3. Emerging and other Communicable Diseases, Surveillance and Control. Control of epidemic meningococcal disease. WHO practical guidelines, 2nd ed. Geneva: WHO, 1998.

4. Riedo FX, Plikaytis BD, Broome CV. Epidemiology and prevention of meningococcal disease. Pediatr Infect Dis J 1995; 14: 643-57.

5. Campagne G, Schuchat A, Djibo S, Ousseni A, Cisse L, Chippaux JP. Epidemiology of bacterial meningitis in Niamey, Niger, 1981-96. Bull WHO 1999; 77: 499-508.

6. Manson-Bahr PEC, Bell DR. Manson's tropical diseases, 20th ed. London: Bailiére Tindall, 1995. United Nations High Commissioner for Refugees. Handbook for emergencies. Geneva, 1982.

7. Tikhomirov E, Santamaria M, Esteves K. Meningococcal disease: Public health burden and control. World Health Stat Q 1997; 50: 170-7.

8. Toole MJ, Foster S. Famines. In: Greeg MB, ed. The public health consequences of disasters. Atlanta GA: CDC, 1989: 79-89.

9. CDC. Famine-affected, refugee, and displaced populations: recommendations for public health issues. MMWR 1992; 41: Issue 13.

10. Moore PS, Toole MJ, Nieburg P, Waldman RJ, Broome $\mathrm{CV}$. Surveillance and control of meningococcal meningitis epidemics in refugee populations. Bull WHO 1989; 67: 381-8.

11. Woods CW, Armstrong C, Sackey SO et al. Emergency vaccination against epidemic meningitis in Ghana: implications for the control of meningococcal disease in West Africa. Lancet 2000; 355: 30-3.

12. Miller MA, Wenger J, Rosenstein N, Perkins B. Evaluation of meningococcal meningitis vaccination strategies for the meningitis belt in Africa. Pediatr Infect Dis J 1999; 18: 1051-9.

13. Mabey D. Bacterial, spirochetal, chlamydial and rickettsial infections. In: Stanfield P, Brueton M, Chan M, Parkin M, Waterston TD, eds. Diseases of children in the subtropics and tropics. London: E Arnold, 1993.

14. Wenger JD, Hightower AW, Facklam RR, Gaventa S, Broome CV. for the Bacterial Meningitis Study Group. Bacterial meningitis in the United States, 1986: report of multistate surveillance study. J Infect Dis 1990; 162: 1316-23. 